\title{
Macroporous Support Coatings for Molecular Separation Membranes having a Minimum Defect Density
}

Paper published in 7 Membr. Sci. 278 (2006)

pp 349-356

Ben C. Bonekamp, Arjan van Horssen, Luci A. Correia, Jaap F. Vente and Wim G. Haije 


\begin{abstract}
Bubble number porometry and $\mathrm{Hg}$ porosimetry were used to investigate the density and size of percolating channels in gross macroporous support tubes, support tubes coated with one or two macroporous $\alpha$-alumina layers and the latter coated with a thin mesoporous $\gamma$-alumina layer. The key factor in obtaining macroporous thin layers with bulk properties is found in the application of multiple layers rather than the use of a single somewhat thicker layer. The breakthrough pressure of the layered macroporous substrate system drastically increases only when two coatings are applied with sufficient total thickness to shield larger voids. The bubble percolation behaviour of a mesoporous $\gamma$-alumina coating is determined by the width of the $\mathrm{Hg}$ intrusion curve of the underlying macroporous substrate coating(s). The average size of the macropore distribution is sufficiently low for building up a sol-gel layer, but the large pores cause percolating channels in the mesoporous $\gamma$-alumina layer of the same size. This leads to a bubble point size/ mean pore size ratio of the $\gamma$-alumina coating $>>1$. The present results show an increase in the reproducibility of the pore properties up to the $\gamma$-alumina layer.
\end{abstract}

Keywords: membrane support, porometry, bubble point, defect size, percolation, reproducibility. 


\section{Contents}

List of tables $\quad 4$

List of figures 4

1. Introduction 5

2. Experimental 8

3. Results 10

4. Discussion 15

5. Conclusions 17

6. List of Symbols 17

$\begin{array}{ll}\text { 7. Acknowledgements } & 17\end{array}$

References 18 


\section{List of tables}

none

\section{List of figures}

Figure 1.1 a. SEM micrograph of the surface of an A1 coating. The bimodal particle size distribution of A1 powder is clearly visible. b. SEM micrograph of the surface of an A6 coating showing a random dense packing of particles

Figure $1.2 \mathrm{Hg}$ intrusion curves and bubble number density curves of $\mathrm{E}, \mathrm{C}$ tubes and $\mathrm{Hg}$ intrusion curve of A6 bulk compact sintered at $1100{ }^{\circ} \mathrm{C}$ and bubble number density curve of E/A1/A6..

Figure 3.1 Flow curves of concentrated A6 suspensions at alumina volume fractions of 0.35, 0.45 and 0.52. Deflocculant concentration is $9 \mathrm{mg}$ per g. alumina in each case.

Figure 3.2 Hg intrusion curves of A6 bulk compacts sintered at different temperatures. The inset shows the normalized curves.

Figure 3.3 The influence of the sinter temperature of $C$ tubes coated with two A6 layers $(2 x \sim 40 \mu m)$ on the bubble number porometry curves.

Figure 3.4 a. Large defect in A6 layer identified with bubble porometry. $b$. Area where bubbles in the Laplace diameter range 0.2-0.5 $\mu$ m (curvature 8-20/ $\mu \mathrm{m}$ ) appeared. Sinter temperature $1200^{\circ} \mathrm{C}$.

Figure 3.5 The influence of the thickness of a single A6 layer coated on a $C$ support on the bubble number porometry curve. All A6 layers were sintered at $1100^{\circ} \mathrm{C}$.

Figure 3.6 Bubble number porometry curves of $C$ tubes coated with two A6 layers, with various thicknesses, and one $C$ tube coated with two A6 layers and a $\gamma$ layer. All A6 layers were sintered at $1200^{\circ} \mathrm{C}$.

Figure 3.7 Comparison between the bubble number porometry curves of the C/A6/A6/ $\gamma$ system and the reference E/A1/A6/ $\gamma$ system. All A6 layers were $\sim 40 \mu \mathrm{m}$ thick. The sinter temperature was $1100^{\circ} \mathrm{C}$ and $1200^{\circ} \mathrm{C}$ respectively. 


\section{Introduction}

Supported microporous layers with pores smaller than $1 \mathrm{~nm}$ can be used as a molecular separation membrane (MSM) for the separation of gases or liquids (see e.g. [1,2]). The separating layer of such a membrane system is usually $\sim 100 \mathrm{~nm}$ thick. In the case of perfect layers, the pore characteristics, such as pore size distribution, tortuosity, and connectivity, are the determining factor for the separation performance. This performance is further influenced by the physical chemical properties of the solid-fluid interfaces. The selectivity decreases when channels are present that are much larger than the intrinsic pore size. These so-called defect pores are formed during the dip-coating process, due to asperities, larger voids, and dust particles, or during the drying/consolidating stage, due to shrinkage and interaction with the substrate. It is obvious that the concentration of imperfections must be kept as low as possible. One of the requirements to obtain such a layer is a support structure that is smooth, flawless and homogeneous. Although the above is recognised in the membrane literature no quantitative information in this respect is available in the open literature. Defect structures in porous coatings can be studied by comparing $\mathrm{Hg}$ porosimetry of bulk material with bubble porometry of coatings of the same material. In Hg porosimetry the intrusion volume of non-wetting $\mathrm{Hg}$ is measured as a function of pressure (see e.g. [3]). Here vacuum ("wetting phase") is displaced from the outside by $\mathrm{Hg}$. In bubble number porometry (see e.g. [4]) the displacement of a wetting fluid (i.e. ethanol) by $\mathrm{N}_{2}$ (non-wetting fluid) as a function of pressure (difference) is measured by counting the appearance of bubbles. Hence in both cases a non-wetting fluid displaces a wetting phase from the outside of the porous material. Such processes are called invasion percolation processes [5]. In the early nineties, ECN developed a tubular macroporous support system that was used for the application of mesoporous ultrafiltration layers [2]. This support system consisted of a gross macroporous alumina support tube (E) coated with two thick $(\sim 40 \mu \mathrm{m})$ macroporous alumina coatings (A1 and A6), denoted as E/A1/A6. The ultrafiltration membrane was completed by adding a $2 \mu \mathrm{m}$ thick mesoporous $\gamma$-alumina coating. This fourlayer system was in turn used as support in the development of microporous MSM [2]. In this paper this system or its constituents will be used for comparison purposes only. As the mean intrinsic pore size of the $\gamma$-alumina layer is $\sim 4 \mathrm{~nm}$, we expect that the maximum size of the pores is $\sim 10 \mathrm{~nm}$. Still, we have been aware that this system contained a small amount of defects with a characteristic size of 1 to $4 \mu \mathrm{m}$. However, only recently we discovered the presence of more than $1000 / \mathrm{dm}^{2}$ percolating voids in the size range 0.2 to $0.4 \mu \mathrm{m}$. These defects are present despite careful colloidal processing (see e.g. [6,7]) and the use of a clean room. We suspected that the defect channels in the $\gamma$-alumina coating originate from the macroporous support system underneath. Careful consideration of the properties of the constituting layers yielded the first macroporous layer (A1) on top of this support as the main suspect. We found indeed that by replacing the A1 layer by the finer A6 layer the defect density decreased appreciably whether we used our own in house developed substrate tubes $\mathrm{E}$ or commercial ones $\mathrm{C}$. Because the use of commercial tubes was the more logical choice having in mind a commercially producible system, we decided to do further optimising of a MSM support system using the commercial tubes $\mathrm{C}$. The curvature where $\mathrm{Hg}$ intrusion breakthrough occurs is the percolation point where a connective sample spanning $\mathrm{Hg}$ cluster is formed. In the optimal case the bubble point should coincide with the $\mathrm{Hg}$ intrusion threshold. The differences in the powders A1 and A6 can be assessed from Figure 1.1. 


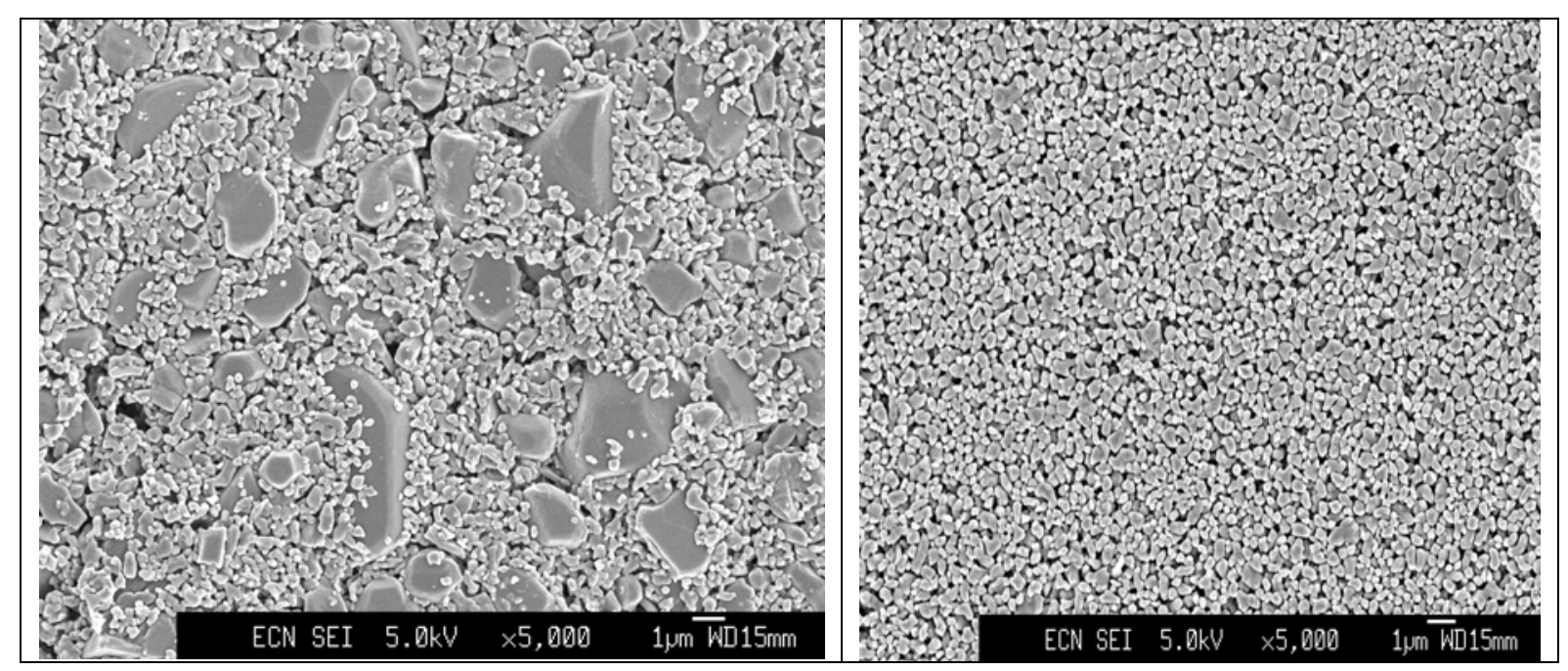

Figure 1.1 a. SEM micrograph of the surface of an A1 coating. The bimodal particle size distribution of A1 powder is clearly visible. $b$. SEM micrograph of the surface of an A6 coating showing a random dense packing of particles

Powder A1 displays clearly a bimodal particle size distribution, where powder A6 is monomodal. The $\mathrm{Hg}$ intrusion threshold for bulk A6 suspension compacts occurs at a pore curvature of $23 / \mu \mathrm{m}$, i.e. at a Laplace diameter $\mathrm{d}_{\mathrm{L}}=174 \mathrm{~nm}$ (Figure 1.2).

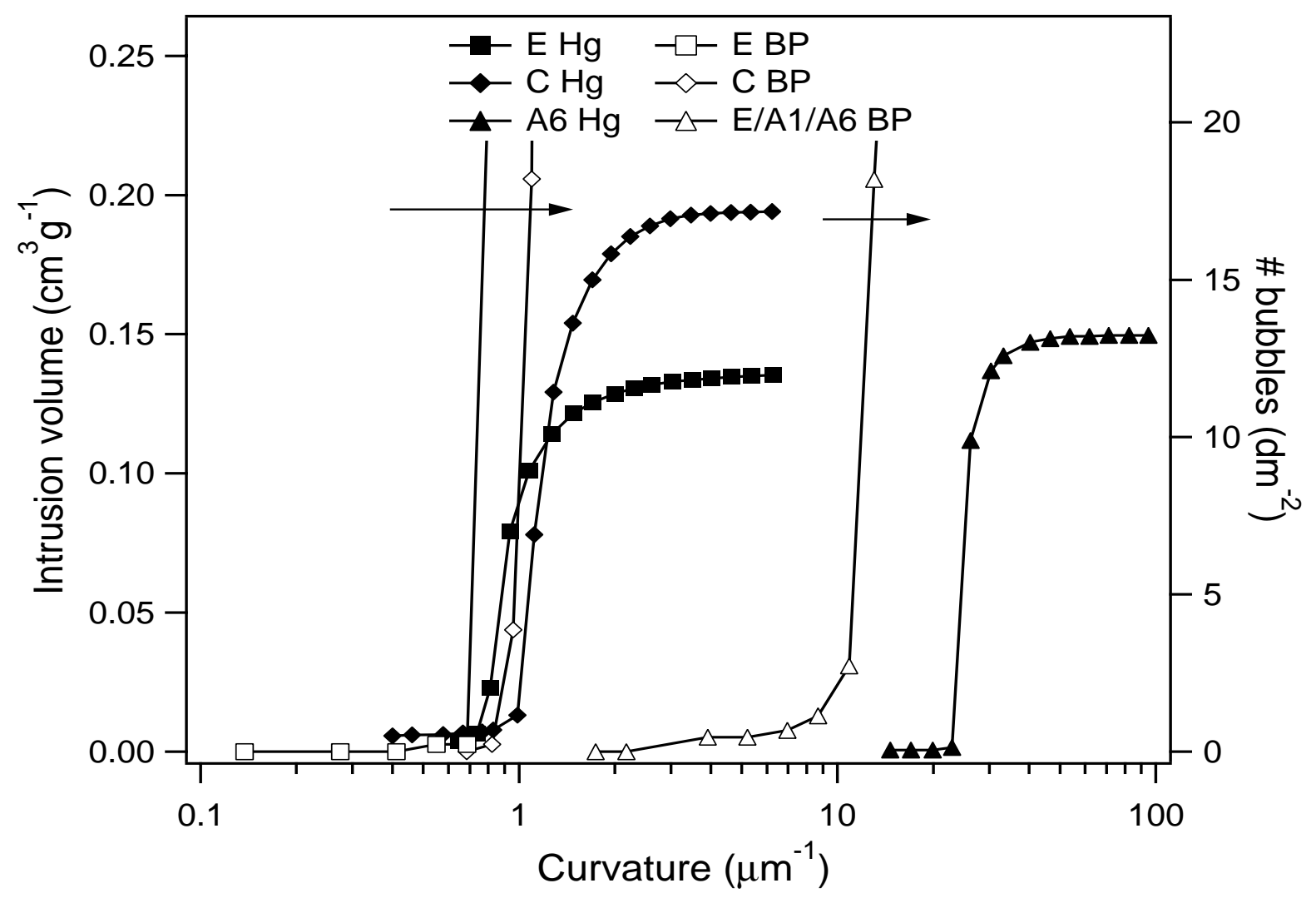

Figure 1.2 $\mathrm{Hg}$ intrusion curves and bubble number density curves of $\mathrm{E}, \mathrm{C}$ tubes and $\mathrm{Hg}$ intrusion curve of A6 bulk compact sintered at $1100^{\circ} \mathrm{C}$ and bubble number density curve of E/A1/A6 
The bubble point of the E/A1/A6 system occurs around $d_{L}=600 \mathrm{~nm}$ (curvature $\sim 7 / \mu \mathrm{m}$ ). This value is clearly larger than the $\mathrm{Hg}$ breakthrough diameter and of the same order or even somewhat larger than that of the interstitial particle voids, $200-500 \mathrm{~nm}$, as estimated from Scanning Electron Microscopy pictures (Figure 1b). So, the E/A1/A6 system does not behave as an A6 bulk compact at all. The objective of the current study is to prepare a macroporous support system using A6 layers, with bulk properties, on a commercial substrate. The bubble point curve of the gamma coating can then be used as an indicator for the improvement achieved. To this end, we investigated the properties of macroporous and mesoporous layers with respect to the percolating void properties with bubble number porometry and compared these with $\mathrm{Hg}$ porosimetry results of unsupported bulk material. We will show that a substantial decrease in the defect population of mesoporous $\gamma$-alumina substrates for molecular separation membranes can be achieved by changing the macroporous layer system. Further, we will show that the key factor in obtaining thin layers with bulk properties is found in the application of multiple layers rather than the use of a single somewhat thicker layer using monomodal particle suspensions. 


\section{Experimental}

\section{Substrate tubes}

Coarse macroporous substrate tubes (coded C) were used in the experiments. These tubes are reproducibly made on an industrial scale. The porosity and d50 pore size of the $\mathrm{C}$ tubes are 0.43 and $3.4 \mu \mathrm{m}$ respectively. The diameter is $14.0 \mathrm{~mm}$ and the wall thickness is $2.0 \mathrm{~mm}$. The outer surface of the $\mathrm{C}$ tubes is about twice as smooth as that of the $\mathrm{E}$ tubes as measured with a mechanical profilometer.

\section{Preparation of porous coatings}

High purity $\alpha$-alumina powder (coded A6) was used for the preparation of aqueous suspensions. The A6 powder has a narrow primary particle size distribution $(0.4-0.6 \mu \mathrm{m})$ and a specific surface area of $4-6 \mathrm{~m}^{2} / \mathrm{g}$. The powders were calcined for $2 \mathrm{~h}$ at $600^{\circ} \mathrm{C}$ before use. Suspensions were prepared by mixing and deagglomerating the powder with water in an attritor, using a polyelectrolyte deflocculant. Subsequently, the suspensions were aged and deairated. Shortly before the preparation of a coating, a non-ionic wetting agent was added [2]. $\alpha-\mathrm{Al}_{2} \mathrm{O}_{3}$ bulk compacts were prepared by quickly drying a few $\mathrm{ml}$ of suspension at $70^{\circ} \mathrm{C}$, followed by sintering analogous to the respective coatings. Coatings were prepared by filmcoating [8]. The tubes were pretreated as described in [2] to obtain a static contact angle with water of about $110^{\circ}$. This secured the absence of capillary suction during suspension coating. Hence particle packing occurs only by drying the wet suspension layer. Coating experiments were performed at least in triplicate. Tube lengths were $30 \mathrm{~cm}$ unless stated otherwise. To prevent the formation of bubbles in the freshly prepared coatings, the tubes were first dried at room temperature. Subsequently, the tubes were heated to $1100-1300^{\circ} \mathrm{C}$ for 2 hours. Heating and cooling rates were $100^{\circ} \mathrm{C} / \mathrm{h}$. The layer thickness (typically $40 \mu \mathrm{m}$ ) of the coating was calculated from coat mass and the porosity obtained from $\mathrm{Hg}$-porosimetry was typically about $37 \%$ for material sintered at $1100^{\circ} \mathrm{C}$. $\mathrm{HCl}$ peptised Boehmite sols were synthesised following the procedure of Leenaars [9] and Yoldas [10], using P.A. grade aluminium secondary butoxide, $\mathrm{HCl}$, and Milli Q water. Sols were stored in polyethylene bottles at $4^{\circ} \mathrm{C} . \gamma-\mathrm{Al}_{2} \mathrm{O}_{3}$ films were prepared by drying a small amount of the sol layer at room temperature and subsequent sintering of the dried material. Boehmite coatings were applied on the $\alpha-\mathrm{Al}_{2} \mathrm{O}_{3}$ substrates in a clean room by colloidal filtration. After ambient drying the coating was calcined at $600^{\circ} \mathrm{C}$ for 5 hours. Heating and cooling rate were $50^{\circ} \mathrm{C} / \mathrm{h}$.

\section{Rheology}

Rheological properties of the suspensions were determined at $20^{\circ} \mathrm{C}$ with a TA Instruments CSL2 constant stress rheometer using a double concentric cylindrical measuring cup. The suspensions were pre-sheared at $20 \mathrm{~Pa}$ for $60 \mathrm{~s}$. After $10 \mathrm{~s}$ rest, the first ramp from low to high shear stress was made, directly followed by a ramp down and a ramp up again. Each ramp took 5 min. At each stress setting a fixed equilibration time was taken. The solid content of a suspension was determined gravimetrically.

\section{Porosimetry}

$\mathrm{Hg}$ intrusion curves were recorded with a Micromeretics Autopore type II 9220. Samples of bulk material were evacuated $(30 \mu \mathrm{m} \mathrm{Hg}$ ) at room temperature for at least $45 \mathrm{~min}$. Equilibrium times between pressure settings were $10 \mathrm{~s}$. Results are reported with blank corrections. The intrusion pressure was rescaled to the Laplace diameter using the Laplace equation:

$$
\Delta P=\frac{4 \gamma}{d_{L}} \cos \theta(1),
$$


where $\gamma$ is the surface tension of the liquid-fluid interface, $d_{L}$ the capillary diameter, and $\theta$ is the contact angle of the wetting fluid with capillary wall. In order to compare Hg-porosimetry data with bubble porometry data it is convenient to define the void curvature $\mathrm{J}$ as follows:

$$
J=\frac{\Delta P}{\gamma \cos \theta}=\frac{4}{d_{L}}(2),
$$

In case of good wetting, i.e. $\cos \theta=1$ and $\mathrm{J}$ is the same as the meniscus curvature $\Delta \mathrm{P} / \gamma$. The surface tension of $\mathrm{Hg}$ was taken as $480.0 \mathrm{mN} / \mathrm{m}$ and the $\mathrm{Hg} /$ alumina contact angle as $141.3^{\circ}$.

Bubble porometry on tubular substrate and supported layers for the determination of the bubble point and the bubble number curve at higher pressures were performed by closing one end of the tube and connecting the other to a pressure controlled $\mathrm{N}_{2}$ supply. The $\mathrm{N}_{2}$ pressure was increased in a stepwise manner to ensure a stationary state at each pressure setting. The tubes were wetted in either pure water or ethanol before the experiment. The $\mathrm{N}_{2}$ pressure where the first bubble appeared on the outer surface is the bubble point pressure. The number of bubbles is recorded as function of increasing pressure until the number density was too large to be counted. In all bubble porometry experiments presented the bubbles appeared randomly distributed over the surface. Duplicate measurements lead to identical results. We define the bubble breakthrough pressure as the extrapolation of the bubble density curve to zero bubble density.

\section{Microscopy}

Optical stereomicroscopy was used to inspect spots on the tubes were bubbles appeared first and to facilitate the preparation of samples for analysis by Scanning Electron Microscopy (SEM), using a Jeol J6330F. 


\section{Results}

\section{Rheology}

Figure 3.1 shows that the A6 coating suspensions are shear thinning. As expected, the shear thinning character increases with increasing volume fraction. No indication of thixotropy was observed and we conclude that the suspensions are in a weakly agglomerated state. The agglomerate structure prevents excessive draining after film coating, and ensures a homogeneous layer thickness. The increase of the viscosity of the suspensions with increasing volume fraction follows the Dougherty-Krieger equation (see e.g. [11]). Fitting the high stress viscosity as function of the solids volume fraction to this relation lead to an intrinsic viscosity of 4 and a maximum packing fraction of 0.6. For comparison, the respective values for random close packed spheres are 2.5 and 0.63 [11,12]. These results suggest that the presence of agglomerates in the A6 suspension does not prevent the occurrence of random dense packing.

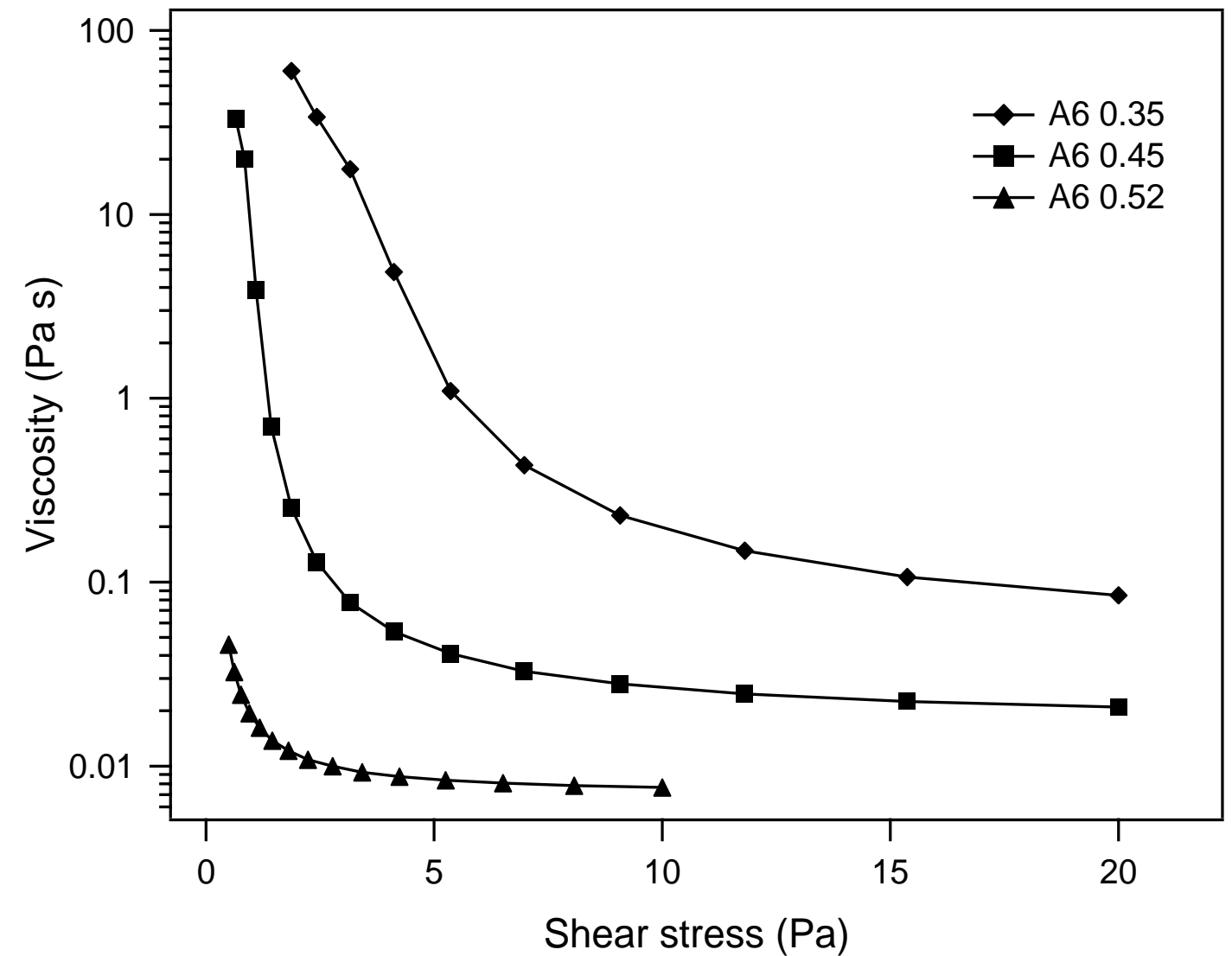

Figure 3.1 Flow curves of concentrated A6 suspensions at alumina volume fractions of 0.35, 0.45 and 0.52. Deflocculant concentration is $9 \mathrm{mg}$ per $\mathrm{g}$. alumina in each case.

Sinter properties $A 6$ compacts and thin layers

In Figure 3.2 the $\mathrm{Hg}$ intrusion curves are shown for different sintering temperatures of the A6 compacts. The normalised curves in the inset indicate that in this temperature window no change in packing mode (e.g. pore structure) occurs. The situation is different for a thin supported layer. The substrate material is already sintered at high temperature before application of the coatings and shows only linear expansion upon heating in the temperature range relevant for this study. 


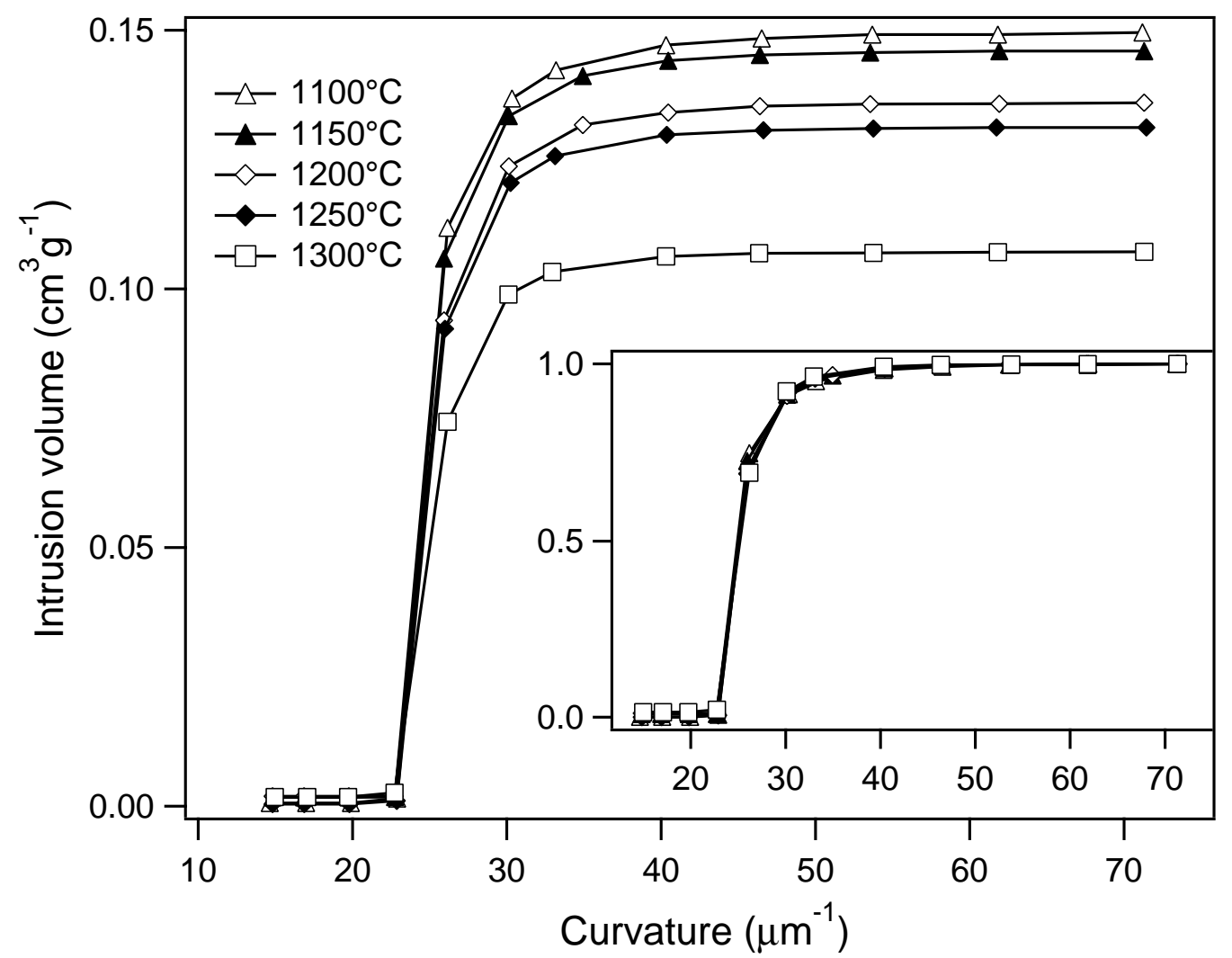

Figure $3.2 \mathrm{Hg}$ intrusion curves of A6 bulk compacts sintered at different temperatures. The inset shows the normalized curves.

As a result constrained sintering and the build up of tensile stresses may occur at sinter temperatures were bulk shrinkage occurs leading to the formation of microcracks. This explains the increase in bubble density when the $\mathrm{C} / \mathrm{A} 6 / \mathrm{A} 6$ system is sintered above $1150^{\circ} \mathrm{C}$ (Figure 3.3).

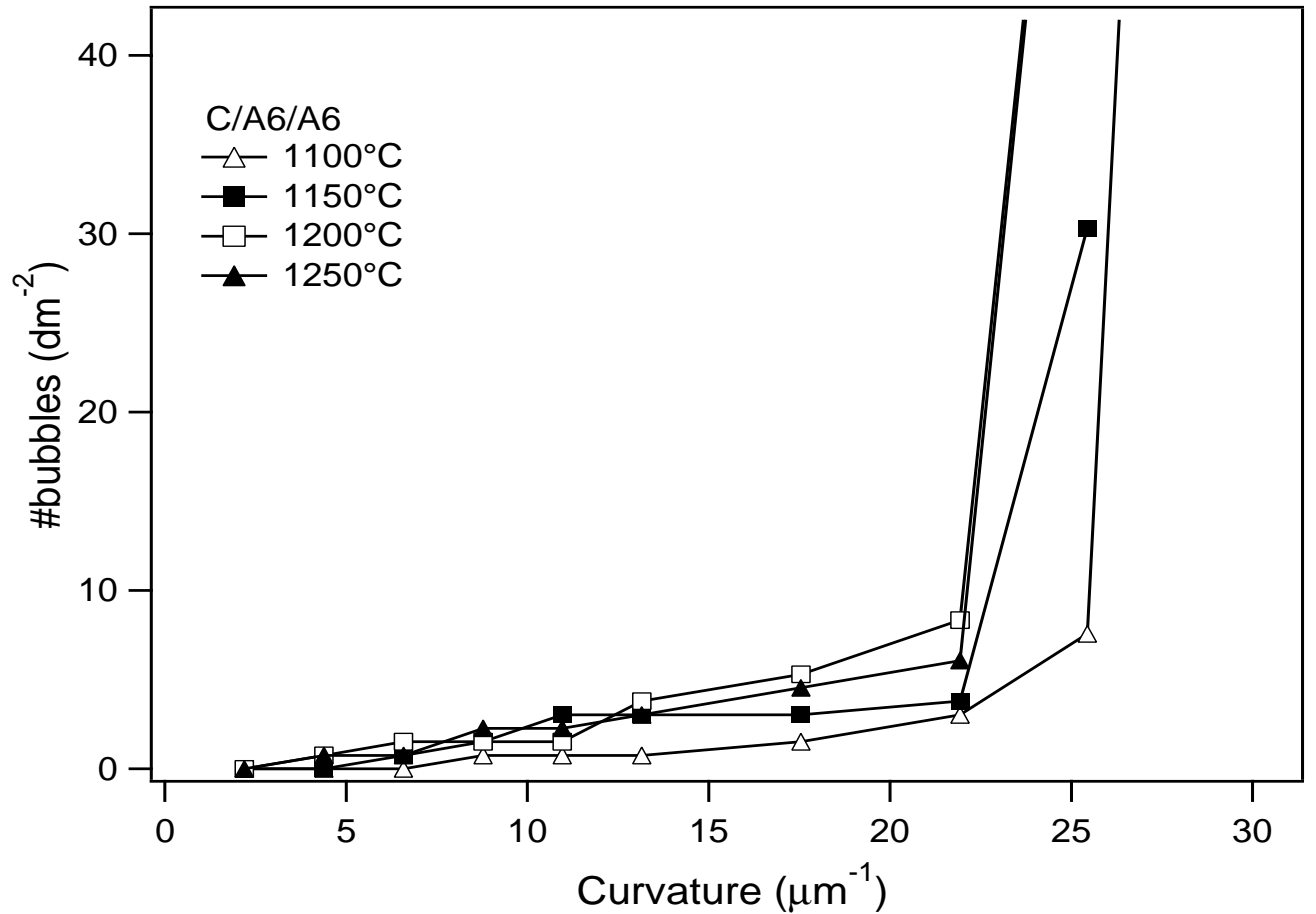

Figure 3.3 The influence of the sinter temperature of $C$ tubes coated with two A6 layers $(2 x \sim 40 \mu m)$ on the bubble number porometry curves. 
Defects pores in A6 layers

Figure 3.4a shows a SEM micrograph of a coating defect at a location where a bubble at low curvature (low pressure, large size) occurred. Figure $3.4 \mathrm{~b}$ shows an area where bubbles evolved at a Laplace diameter of $\sim 0.4 \mu \mathrm{m}(\mathrm{J} \sim 10 / \mu \mathrm{m})$ close to the breakthrough curvature of the bulk A6 (Figure 1.2). The microstructure of the A6 coatings appears to be rather disordered and dense. The domain structure observed could be somewhat different than that expected by purely random packing due to the attractive interaction energy of the particles in the suspension. Still, we believe that considering the A6 particle compacts as being randomly packed is a good first approximation.

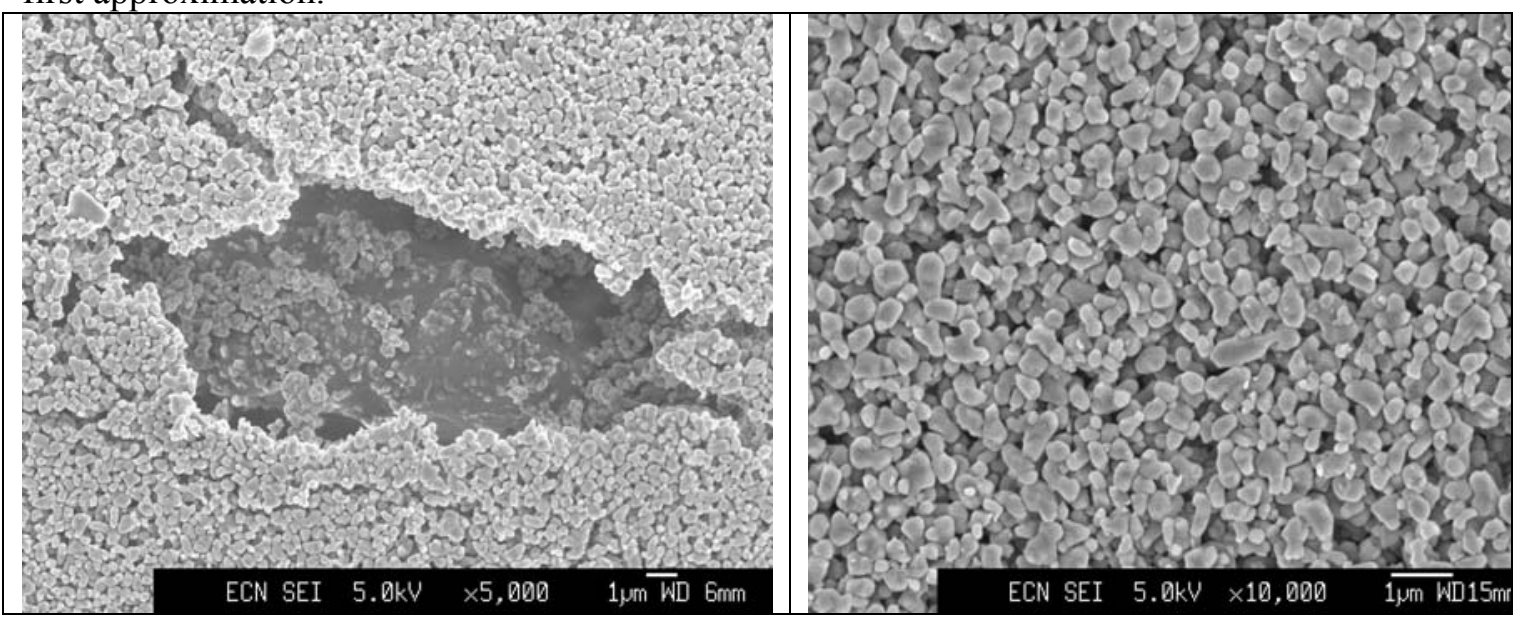

Figure 3.4 a. Large defect in A6 layer identified with bubble porometry. $b$. Area where bubbles in the Laplace diameter range 0.2-0.5 $\mu \mathrm{m}$ (curvature 8-20/ $\mu \mathrm{m}$ ) appeared. Sinter temperature $1200^{\circ} \mathrm{C}$.

Single and double A6 coatings

Figure 3.5 shows the effect of the layer thickness of single A6 coatings on the bubble number density curve. We observed that a thicker single coating does not shift the bubble point curvature to higher values compared to that of a bare substrate $(\mathrm{C})$. Only lower slopes are observed.

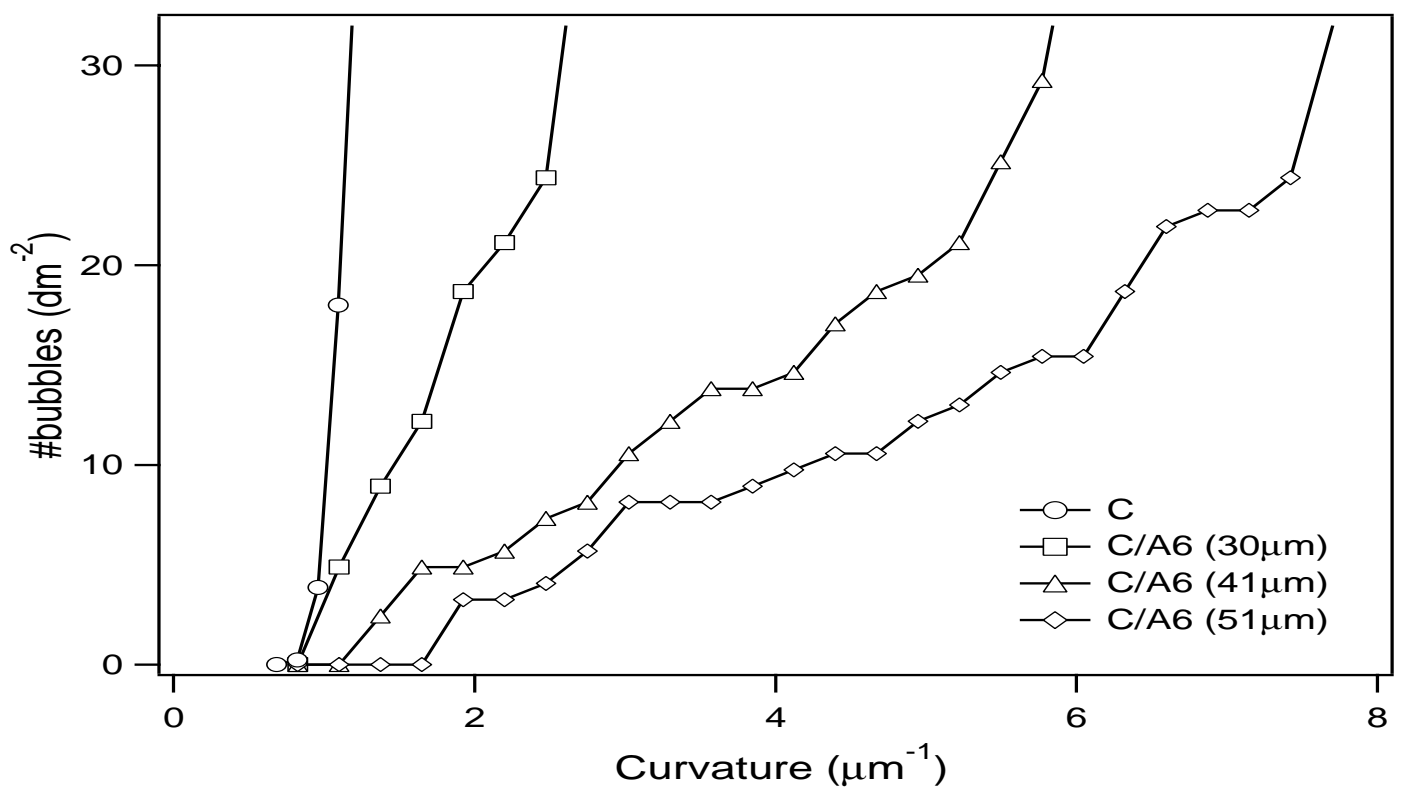

Figure 3.5 The influence of the thickness of a single A6 layer coated on a $C$ support on the bubble number porometry curve. All A6 layers were sintered at $1100^{\circ} \mathrm{C}$ 
Figure 3.6 shows the influence of the stacking sequence of two A6 layers on the bubble point curve. Coating first a thick $(\sim 40 \mu \mathrm{m})$ and then a thin $(\sim 15 \mu \mathrm{m})$ layer is not significantly better than a single coating of the same total thickness. However, coating first a thin $(\sim 15 \mu \mathrm{m})$ layer and than a thicker one $(\sim 40 \mu \mathrm{m})$ results in a shift to higher bubble point curvature and a much larger decrease in slope. An even better result is obtained when two thick layers $(\sim 40 \mu \mathrm{m})$ are applied. This double A6 coating appears to shift the bubble point curvature to about $22 / \mu \mathrm{m}$. This is precisely the $\mathrm{Hg}$ breakthrough curvature of $\mathrm{A} 6$ bulk compacts of the same suspension. A tentative explanation is that this is caused by the low probability that a percolating channel larger than the infinite threshold continues in the second layer as well as by smoothing of the substrate by the first layer. Too thin layers may contain unshielded large voids preventing a shift to a higher breakthrough curvature when a thin layer of $15 \mu \mathrm{m}$ is coated on a thicker first layer. After coating a $\gamma$-alumina layer on the improved C/A6(40 $\mu \mathrm{m}) / \mathrm{A} 6(40 \mu \mathrm{m})$ system we see only a slight shift in the bubble point curvature to higher values. When we increase the pressure beyond the bubble point we still observe a strong increase in bubble number density.

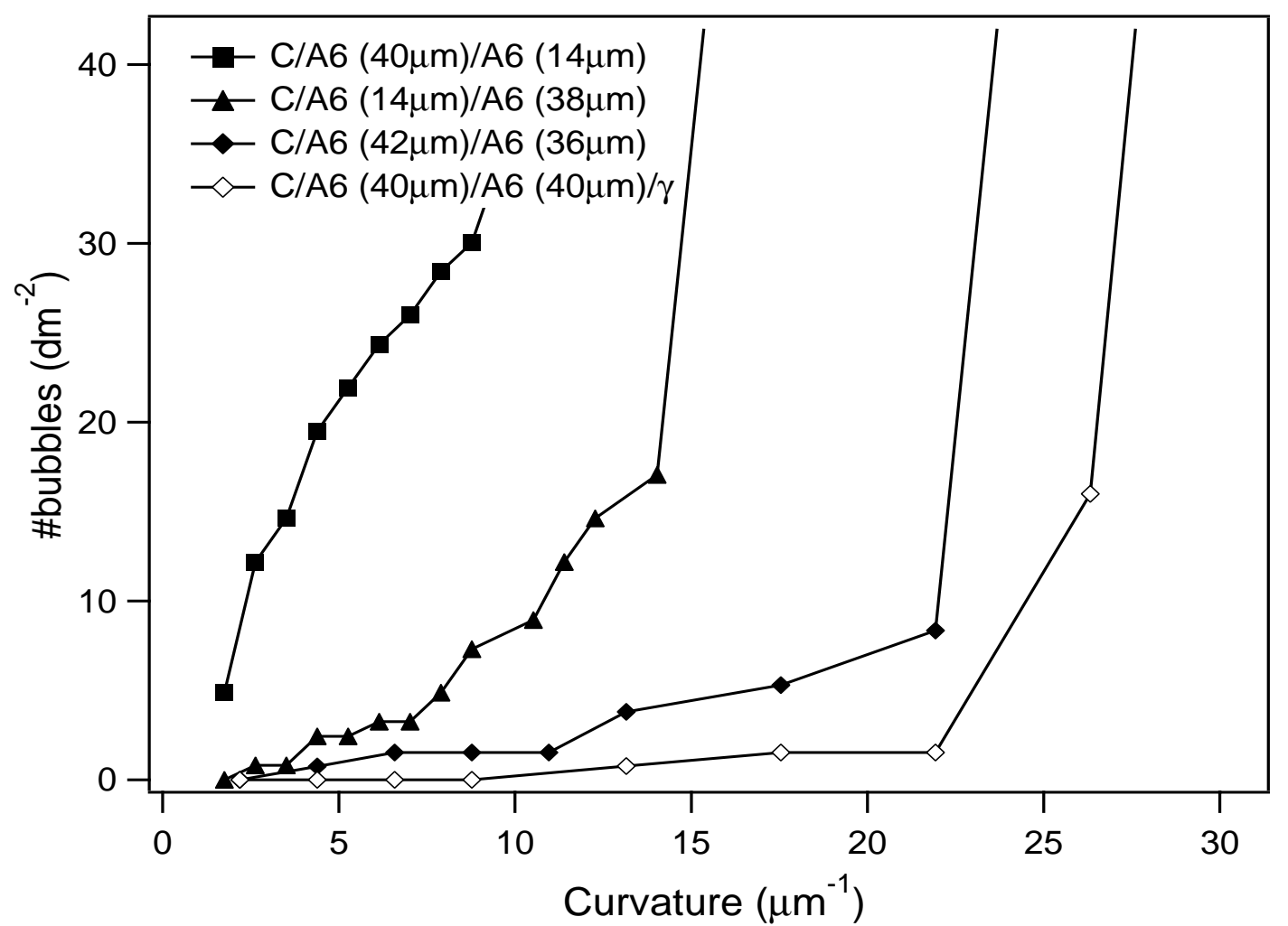

Figure 3.6 Bubble number porometry curves of $C$ tubes coated with two A6 layers, with various thicknesses, and one $C$ tube coated with two A6 layers and a $\gamma$ layer. All A6 layers were sintered at $1200^{\circ} \mathrm{C}$.

\section{Reproducibility}

In Figure 3.7 we show bubble porometry curves of different specimens of the 4-layer mesoporous support system $\mathrm{C} / \mathrm{A} 6 / \mathrm{A} 6 / \gamma$ and compare these with curves of the reference system E/A1/A6/ $\gamma$. Note that the comparison here concerns scaled up tube lengths to $90 \mathrm{~cm}$ in both cases. The systems $\mathrm{C} / \mathrm{A} 6 / \mathrm{A} 6 / \gamma$ have two macroporous $\alpha$-alumina A6 layers with both a thickness of about $40 \mu \mathrm{m}$. The $90 \mathrm{~cm}$ tube systems $\mathrm{C} / \mathrm{A} 6 / \mathrm{A} 6 / \gamma$ and $\mathrm{E} / \mathrm{A} 1 / \mathrm{A} 6 / \gamma$ were sintered at respectively $1100^{\circ} \mathrm{C}$ and $1200^{\circ} \mathrm{C}$. The $\gamma$-alumina layer on the $\mathrm{C} / \mathrm{A} 6 / \mathrm{A} 6 / \gamma$ system has a bubble point curvature of about $22 / \mu \mathrm{m}$ with a narrow distribution. The ratio breakthrough size/average A6 pore size is about 1.2 for the C/A6/A6 system and varies between 4 and 10 for the E/A1/A6 
system. So the difference is almost one order of magnitude. We observed that the breakthrough size of the gamma layer is always about the same as that of the macroporous substrate. However, the slope of the bubble density-curvature plot is lower. The spread in bubble curvature is clearly much smaller for $\mathrm{E} / \mathrm{A} 6 / \mathrm{A} 6 / \gamma$ than that of $\mathrm{C} / \mathrm{A} 1 / \mathrm{A} 6 / \gamma$.

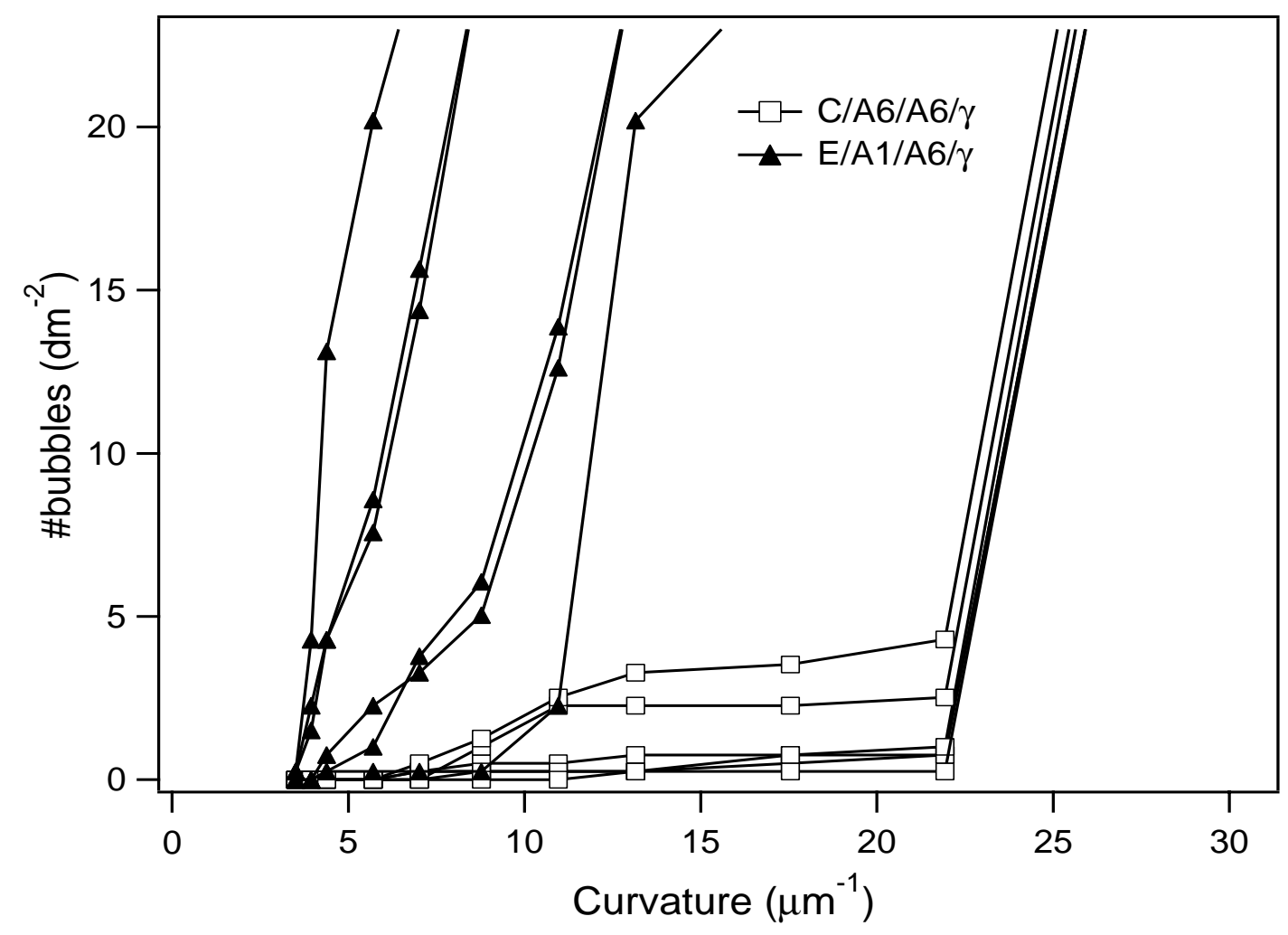

Figure 3.7 Comparison between the bubble number porometry curves of the C/A6/A6/ $\gamma$ system and the reference E/A1/A6/ $\gamma$ system. All A6 layers were $\sim 40 \mu \mathrm{m}$ thick. The sinter temperature was $1100^{\circ} \mathrm{C}$ and $1200^{\circ} \mathrm{C}$ respectively. 


\section{Discussion}

Bubble number porometry is a very sensitive technique for detecting the largest percolating channel (the breakthrough point). We assume that the bubbles counted at a certain pressure are all caused by percolating channels with a narrowest size corresponding to the curvature determined by the Laplace relation. We think that the effect recently discovered by [13] is not relevant in our case. These authors showed that bubbles appearing above the bubble point pressure can still be of the same size as that of the first bubble due to a decrease of the pressure below a bubbling channel. This prevents the bubbling of a nearby (i.e. $<10$ defect diameters) percolation channel of the same size and higher pressures are needed before the bubbling of this channel starts. The distance between percolating defects of about the breakthrough size is in our case too large for the pressure decrease mechanism to be operative in our case.

The breakthrough pressure of random A6 particle packing obtained by extrapolation of $\mathrm{Hg}$ intrusion in the region of massive intrusion to zero intrusion represents the breakthrough pressure of "infinite" random A6 compacts. Large size percolating channels remain unnoticed in $\mathrm{Hg}$ porosimetry and do not affect the breakthrough point of the random bulk compact. Channels much larger than the largest particle interstices are, however, easily detected in bubble number porometry. If the breakthrough curvature of a coating is still below that of a bulk sample (i.e. infinite network), a decreasing slope at a certain curvature $\mathrm{J}$ corresponds to a decreasing density of large size percolating voids in the structure. When the bubble point curvature of a coating is the same as the breakthrough point of a random bulk compact, we believe that the structure of the coating is the same as that of an "infinite" random particle compact. In that case the slope of a bubble density-curvature plot reflects the percolating channel properties of an undisturbed random packing of particles. In this case, the maximum breakthrough curvature is reached and the lowest percolating defect density is obtained. Improvement is only possible when another powder is being used. Qualitatively, the bubble density-curvature relation can than be seen as a sort of weighed pore neck size distribution [14,15], just as the Hg-intrusion curve of the bulk compact. Pore models that include the pore connectivity are needed for a quantitative interpretation of the slope of the porometry curves above the breakthrough threshold in terms of changes in pore frequency. Simple interpreting $\mathrm{Hg}$ intrusion data or bubble porometry data as if the medium consists out of a bundle of capillaries can be misleading [14]. Extensive literature exists which describes models, e.g. percolation theory [16], showing how to deconvolute porosimetry data to obtain pore distributions [15,17-19]. However, this is beyond the scope of this paper. The replacement of the coarse bimodal A1 layer by an A6 layer led to a macroporous A6 system showing bulk properties, i.e. having the same breakthrough point as a bulk A6 compact. The number of defects larger than $0.2 \mu \mathrm{m}$ has decreased from $\sim 1000 / \mathrm{dm}^{2}$ in the case of E/A1/A6/ $\gamma$ to almost nil in the case of C/A6/A6/ $\gamma$. Further, the curvature where the bubble number density becomes "infinite" has shifted from a curvature of on average $12 / \mu \mathrm{m}$ (somewhere between $2 / \mu \mathrm{m}$ and $22 / \mu \mathrm{m}$ ) for the E/A1/A6/ $\gamma$ to $\geq 22 / \mu \mathrm{m}$ for the C/A6/A6/ $\gamma$. It is clear that the newly developed support system is superior over the reference system especially when the increased reproducibility is taken into account. Single A6 coatings were in all cases considerably worse. In thin layers the so-called finite size effects [5,20,21] can become important. For an infinite network the percolation transition is very sharp and no percolating paths are present below the transition. However if the network size is small, but otherwise the same, i.e. an ideal thin layer, the percolation transition becomes fuzzier. In terms of bubble porometry this means that bubbles will appear below the percolation threshold at sizes up to the about the largest void size in the random particle packing (i.e. about $600 \mathrm{~nm}$ in case of A6). Percolation theory predicts that finite size effects become important when the network size is smaller than about 60 nodes of the network [5]. This corresponds to $\sim 100$ particle diameters, or 
a $\sim 60 \mu \mathrm{m}$ thick A6 layer. However our single coatings show also channels of the median pore size of the C support. The "finite size effect" can be responsible for this in the sense that these larger voids in the single layer packing are not shielded [14] if the layer is too thin. The formation of this defect structure must be connected to the particle packing mechanism during filmcoating and drying. Besides the disturbance of the packing by the large pores and/or roughness of the substrate a minor contribution of the suspension processing itself cannot be excluded. However, by coating twice we obtained bulk behaviour in the C/A6/A6 system when the thickness of both A6 coatings is $40 \mu \mathrm{m}$. We ascribe this to smoothing of the substrate by the first layer and the more ideal packing process occurring for the second layer making the probability that a percolating channel larger than the infinite threshold continues in the second layer low. Note that the $\gamma$-alumina layer breakthrough size $(\sim 180 \mathrm{~nm})$ of the C/A6/A6/ $\gamma$ system is still much larger than its average intrinsic mesopore size of $\sim 4 \mathrm{~nm}[8,9]$, and hence the mesoporous layer can certainly not be considered as having bulk properties. The build up of this $\gamma$-alumina layer by colloidal filtration demands for A6 pores to be small enough to enable fast clogging and apparently on average this is the case. However this condition is, we believe, not fulfilled for larger pores of the distribution (large size tail). We think that these larger A6 pores (not defects!) locally lead to percolating voids in the mesoporous coating much larger than the typical intrinsic mesopore size. By using a finer substrate for the mesoporous coating, the bubble point curvature of this layer can be increased and $\gamma$-alumina sol-gel layers obtained should have only intrinsic mesopores. Another route to improvement may be found in the application of a second mesoporous sol-gel layer covering the large percolation channels of the first. The Boehmite coating sols consists of agglomerates of plate shaped particles [9]. These agglomerates are packed during colloidal filtration and rearranged into a densely packed layer structure during drying. In this film structure inter agglomerate pores could still be present due to incomplete restructuring during drying and calcining. As a result the bubble point curvature may remain appreciably lower than that of the average mesopore size. 


\section{Conclusions}

We have shown that the bubble point curvature of single macroporous coatings is determined by the substrate tube properties. The breakthrough pressure in bubble porometry of the layered A6 substrate system drastically increases when the coating is applied twice and the final thickness is sufficient to shield larger voids to approach "infinite size" percolation behaviour. In that case the ratio bubble point curvature/bulk $\mathrm{Hg}$ intrusion curvature is close to 1 . Further improvement is not possible. We showed that the bubble percolation behaviour of a mesoporous $\gamma$-alumina coating is determined by the width of the pore distribution derived from the $\mathrm{Hg}$ intrusion curve of the underlying substrate coating(s). The average size of the A6 pores is sufficiently small for building up a sol-gel layer but the large size pores of the distribution tail cause percolating channels in the mesoporous gamma layer. The bubble point size/ mean pore size of the $\gamma$-alumina coating is still $>>1$ and needs to be improved. Possible routes to this are the application of macroporous coatings with smaller percolating pores, or by applying two $\gamma$-alumina coatings. The present results show a substantial increase in the reproducibility of the pore properties up to the $\gamma$-alumina layer. These new insights will undoubtedly prove to be essential in the improvement of the reproducibility of microporous molecular separation membranes.

\section{List of Symbols}

A1 Suspension coating from A1 $\alpha$-alumina powder

A6 Suspension coating from A6 $\alpha$-alumina powder

C Commercial porous $\alpha$-alumina tube material

E $\quad \alpha$-alumina tube material developed in house

$\mathrm{d}_{\mathrm{L}} \quad$ Laplace diameter of percolating channel $(\mu \mathrm{m})$

$\mathrm{J} \quad$ Curvature of percolating channel $\left(\mu \mathrm{m}^{-1}\right)$

$\Delta \mathrm{P} \quad$ Pressure difference across layered support system (Pa)

$\gamma \quad$ Surface tension $(\mathrm{mN} / \mathrm{m}) /$ gamma-alumina layer

$\theta \quad$ Contact angle

\section{Acknowledgements}

Financial support from the EET METEOR project (EETK0157) and EET-kiem $01009 / 4800000255$ project is gratefully acknowledged. 


\section{References}

[1] Lin Y.S. Microporous and dense inorganic membranes: current status and prospective, Separ. Purif. Techn. 25 (2001) 39.

[2] Bonekamp, B. C. Preparation of Asymmetric Ceramic Membrane Supports by Dip-Coating, in Fundamentals of Inorganic Membrane Science and Technology., Burggraaf, A. J.; Cot, L., editors; Elsevier: Amsterdam, 1996.

[3] Lowell, S.; Shields, J. E.; Thomas, M. A.; Thommes, M. Characterization of porous solids and powders: surface area, pore size and density; Kluwer Academic Publishers (2004).

[4] Jacobs E., W.J.Koros, Ceramic membrane characterization via the bubble point technique, J. Membr. Sci. 124 (2005) 149.

[5] Sahimi, M., Applications of the percolation theory; Taylor \& Francis (1994).

[6] Lewis J.A., Colloidal processing of ceramics, J. Am. Ceram. Soc. 83 (2000) 2341.

[7] Philipse A.P., B.C.Bonekamp, H.J.Veringa, Colloidal filtration and (simultaneous) sedimentation of alumina and silica suspension: influence of aggregates, J. Am. Ceram. Soc. 73 (1990) 2720.

[8] Terpstra,R.A., B.C.Bonekamp, H.J.Veringa, Preparation, characterization and some properties of tubular alpha alumina ceramic membranes for microfiltration and as a support for ultrafiltration and gas separation membranes, Desalination 70 (1988) 39.

[9] Leenaars A.F.M., K.Keizer, A.J.Burggraaf, The preparation and characterization of alumina membranes with ultra-fine pores, Part 1, Microstructural investigations om non supported membranes, J. Mater. Sci. 19 (1984) 1077.

[10] Yoldas B.E., Alumina gels that form porous transparant alumina, J. Mater. Sci. 10 (1975) 1856.

[11]Barnes, H. A.; Hutton, J. F.; Walters, K., An introduction to rheology; Elsevier (1989).

[12] Nolan G.T., P.E.Kavanagh, The size distribution of interstices on random packing of spheres, Powder Technol. 78 (1994) 213.

[13] Gijsbertsen-Abrahamse A.J., R.M.Boom, A.van der Padt, Why liquid displacement methods are sometimes wrong in estimating the pore size distribution, AIChE. J. 50 (2004) 1364.

[14] Dullien, F. A. L., Porous media, fluid transport and pore structure; Academic Press (1979).

[15] Rigby S.P., R.S.Fletcher, S.N.Riley, Characterization of porous solids using integrated nitrogen sorption and mercury porosimetry, Chem. Eng. Sci. 59 (2004) 41.

[16] Stauffer, D.; Aharoni, A., Introduction to percolation theory; Taylor \& Francis (1994).

[17] Heiba A.A., M.Sahimi, L.E.Scriven, H.T.Davis, Percolation theory of two phase relative permeability, SPE Reservoir Eng. 7 (1992) 123.

[18] Park C.Y., S.K.Ihm, New hypothesis for mercury porosimetry with percolation approach, AIChE. J. 36 (1990) 1641.

[19] Mishra B.K., M.M.Sharma, Measurements of pore size distributions from capillary pressure curves, AIChE. J. 34 (1988) 684.

[20] Rigby S.P., R.S.Fletcher, S.N.Riley, Characterisation of macroscopic structural disorder in porous media using mercury porosimetry, J. Colloid Interface Sci. 240 (2001) 190.

[21] Larson R.G., N.R.Morrow, Effect of sample size on capillary pressure curves in porous media, Powder Technol. 30 (1981) 123. 